\title{
Chinese Investor Sentiment and Stock Returns
}

\author{
Xie Mengni \\ School of Management, Wuhan University of Technology, Wuhan, P.R.China, 430070
}

(E-mail:veraxmn@163.com)

Abstract: To verify the relationship between Chinese investor sentiment and Chinese stock returns, this paper collets data from 2003 to 2015, using principal component analysis method to construct the monthly investor sentiment index, then using Granger test to examine whether Chinese investor sentiment and stock returns can influence each other. Finally, using the empirical analysis to get a conclusion that there is positive relation between investor sentiment and stock market returns.

Key words: Behavioral economics; Investor sentiment; OLS; Stock returns

\section{Introduction}

Traditional financial theory assumes that markets are efficient: the product's price can fully reflect its historical price. However, there are many anomalies cannot explain by this theory, behavioral finance has gradually appeared. Nowadays, more and more academic researches start focus on behavioral economics. Because market participants play an active role in stock market, making investor sentiment become a fashion word. Barberis, Shleffer and Vishny (1998), Daniel, Hirsheifer and subramanyam (1998) according to investor psychology cognition deviation to explain the formation of emotion and its impact on the stock price, BSV model and DHS model were constructed. These studies lay a theoretical foundation for testing the impact of investor sentiment on stock returns. Barberis, Shleifer, and Wurgler (2005) study the influence of investor sentiment on the overall stock market. The study shows that the stock returns can be explained by the investor sentiment. Investor sentiment has important influence on the valuation of assets.

\section{Investor Sentiment Index Construction}

In this paper, the main data gained from CSMAR database and the WIND information database. Reference to the existing researches, this paper selects four indexes: Discount of Close-end Fund(DCEF); Turnover rate(TURN); New account number(KNUM); Consumer confidence index(CCI) as an alternative variable of investor sentiment, using principal component analysis method to construct the monthly investor sentiment index(IS1).

As there may be lags, so a lag values of the four variables (LAG_DCEF, LAG_TURN, LAG_KNUM and LAG_CCI) are also included in the principle component analysis, to get the final monthly investor sentiment index(IS2).

Table 1 shows the basic statistics of the four monthly indicators. Table 2 shows the correlation between the four monthly indicators. It means: first, four indicators are of a huge difference, if added into the regression model directly, it will affect the significance of the date; second, the correlation between the four indexes is high, it will produce multiple linear. Therefore, using principal component analysis method is quite reasonable, it can eliminate the influence of the difference and the correlation.

Table 1 Four Indexes Basic Statistics

\begin{tabular}{c|c|c|c|c|c}
\hline Index & $\mathrm{N}$ & Minimum Value & Maximum Value & Mean Value & $\begin{array}{c}\text { Standard } \\
\text { Deviation }\end{array}$ \\
\hline DCEF & 144 & -40.63 & -0.89 & -16.5024 & 12.11403 \\
TURN & 144 & 3.59 & 35.38 & 14.7945 & 7.36971 \\
KNUM & 144 & 30543 & 9847062 & 845280.403 & 1507584.06 \\
CCI & 144 & 89.9 & 109.9 & 99.0903 & 5.58898 \\
\hline
\end{tabular}


Table 2 Four Indexes Correlation

\begin{tabular}{c|cccc}
\hline Index & DCEF & TURN & KNUM & CCI \\
\hline DCEF & 1 & & & \\
TURN & 0.151 & 1 & & \\
KNUM & 0.090 & 0.440 & 1 & \\
CCI & 0.757 & 0.448 & 0.289 & 1 \\
\hline
\end{tabular}

In the first stage, the principal component analysis method was made on the four indexed and their lag values (eight variables), and the initial investor sentiment index(IS1) was obtained. The principal component analysis results in the first stage are shown in Table 3(after omitting latter four principal components' values and contribution rates.

Table 3 The First Stage Principal Component Analysis

\begin{tabular}{c|ccc}
\hline & Total & \% of Variance & Cumulative \% \\
\hline DCEF & 4.109 & 51.362 & 51.362 \\
TURN & 2.158 & 26.981 & 78.343 \\
KNUM & 0.974 & 12.174 & 90.516 \\
CCI & 0.304 & 3.794 & 94.311 \\
\hline
\end{tabular}

From the table we can see that the first two principal components' values are greater than 1 and the cumulative contribution rate is $78.343 \%$, can be a good reflection of the overall situation. Therefore, select the first two principal components F1, F2, with their respective values as the weight, get the initial investor sentiment index IS1.

$$
I S \mathrm{I}=\left(4.109 F_{1}+2.158 F_{2}\right) /(4.109+2.158)
$$

Table 4 IS1 and Eight Variables Correlation

\begin{tabular}{cccccccc}
\hline DCEF & TURN & KNUM & CCI & LAG_DCEF & LAG_TURN & LAG_KNU & LAG_CCI \\
0.085 & 0.451 & 0.972 & 0.289 & 0.073 & 0.416 & 0.963 & 0.305 \\
\hline
\end{tabular}

According to Table 4, we choose the final four variables: DCEF; TURN; KNUM; LAG_CCI. And second stage principal component analysis results show that the first two principal components' values are greater than 1 and the cumulative contribution rate is $81.334 \%$, therefore take the first two principal components $\mathrm{C} 1$ and $\mathrm{C} 2$.

$$
\begin{aligned}
& C_{1}=0.347 D C E F+0.315 T U R N+0.267 K N U M+0.425 L A G_{-} C C I \\
& C_{2}=-0.539 D C E F+0.455 T U R N+0.569 K N U M-0.254 L A G_{-} C C I
\end{aligned}
$$

With their respective values as the weight, get the final investor sentiment index IS2.

$$
I S 2=\left(2.124 C_{1}+1.129 C_{2}\right) /(2.124+1.129)
$$




\section{Empirical Results}

\subsection{ADF Test}

Due to the uneven data will lead to the error of regression, in order to ensure the accuracy of the results, first using ADF test. The results are as follows:

Table 5 ADF Test Results

\begin{tabular}{c|c|c|c|c}
\hline Variables & t-Statistic & Prob. & Confidence level & Critical values \\
\hline IS2 & -14.0688 & 0.0000 & $1 \%$ & -3.4768 \\
Returns(R) & -13.3157 & 0.0000 & $1 \%$ & -3.4775 \\
\hline
\end{tabular}

According to the ADF test, unit root test results are as follows: IS2 and stock returns' t-statics are less than their critical values, therefore refused to null hypothesis. So we can draw a conclusion that the data is stable, can use statistics software to carry on the regression analysis research directly.

\subsection{Granger Test}

According to Granger test, we can clearly see whether IS2 can cause changes in Returns, thereby can be extended to explore the interaction problems. Results are shown in the table:

Table 6 Granger Test Results

\begin{tabular}{l|c|c}
\hline Null Hypothesis & F-Statistic & Prob. \\
\hline IS2 does not Granger Cause R & 4.0031 & 0.0205 \\
R does not Granger Cause IS2 & 4.4986 & 0.0128 \\
\hline
\end{tabular}

Because 0.0205 and 0.0128 both are less than 0.05 , so reject the null hypothesis, which means IS2 does Granger cause R, and R does Granger cause IS2. In order to test whether the impact of IS2 on R is positive or negative, we use follow model:

$$
R_{i}=\alpha_{0}+\alpha_{1} \Delta I S_{i}+\mu_{i}
$$

Using OLS method to get the regression equation between R and IS2:

$$
R=0.01093+0.01578 * I S 2+\mu
$$

Table 7 Error Stability Test

\begin{tabular}{c|c|c|c}
\hline \multirow{2}{*}{ t-Statistic } & Prob. & Confidence level & Critical values \\
& & & \\
\hline \multirow{2}{*}{-3.6516} & \multirow{2}{*}{0.0059} & $1 \%$ & -3.4775 \\
\cline { 3 - 4 } & & $5 \%$ & -2.8821 \\
\cline { 3 - 4 } & & $10 \%$ & -2.5778 \\
\hline
\end{tabular}

The results show, the ADF statistic is less than critical values in $1 \%, 5 \%, 10 \%$ confidence level, therefore the inspection conclusion is stable. We can draw a conclusion that IS2 and R is co-integration relationship, there is a long-term equilibrium relationship between them. At the same time, it can be seen that IS 2 has a positive impact on R. The coefficient of IS 2 was 0.01578 , indicating that IS 2 rose $1 \%$, R increased by $0.0157 \%$. 


\section{Conclusion}

To investigates the relationship between Chinese investor sentiment and stock returns, this paper proposes a new investor sentiment index and finds that investor sentiment is a positive predictor of stock returns: investor sentiment rise $1 \%$, stock returns will increase by $0.0157 \%$.

The revelations are as follow. We should make full use the relationship between Chinese investor sentiment and stock returns while avoiding disadvantages. In the aspect of information disclosure, information asymmetry which can lead to drastic changes in investor sentiment should be avoided.

\section{References}

[1] Brown G, Cliff M. Investor Sentiment and Asset Valuation [J]. Journal of Business, 2005, Vol.7 8, (2): 405-440

[2] Baker Malcolm and Jeremy Stein, Market liquidity as a sentiment indicator[J]. Journal of Financ ial Markets,2004,7: 27 1 -299

[3] Brown, G. W.,M. T. Cliff. Investor Sentiment and Asset Valuation. The Journal of Business,200 5, 78(2): 405

[4] Andersen, T., T. Bollerslev, F. Diebold, and H. Ebens. 2001. The distribution of realized stock r eturn volatility. Journal of Financial Economics 61:43-76

[5] Ang, A., and G. Bekaert. 2007. Return predictability: Is it there? Review of Financial Studies 20: 651-707.

[6] Baker, M., J. Wurgler, and Y. Yuan. 2012. Global, local, and contagious investor sentiment. Jou rnal of Financial Economics 104:272-87

[7] Campbell, J., and S. Thompson. 2008. Predicting the equity premium out of sample: Can anythi ng beat the historical average? Review of Financial Studies 21:1509-31

[8] Cavaliere, G., A. Rahbek, and A. Taylor. 2010. Cointegration rank testing under conditional het eroskedasticity. Econometric Theory 26:1719-60

[9] Henkel, S., J. Martin, and F. Nardari. 2011. Time-varying short-horizon predictability. Journal o f Financial Economics 99, 560-80

[10] Kelly, B., and S. Pruitt. 2013. Market expectations in the cross-section of present values. Journ al of Finance 68:1721-56 